Original Article

\title{
Risk factors for peripheral neuropathy in patients with diabetes mellitus
}

\author{
Taslima Akter ${ }^{1}$, Qazi Shamima Akhter ${ }^{2}$, Zinat Ara Polly ${ }^{1}$, Smita Debsarma $^{3}$ \\ ${ }^{1}$ Department of Physiology, Ibrahim Medical College, Dhaka; ${ }^{2}$ Department of Physiology, Dhaka Medical \\ College, Dhaka, ${ }^{3}$ Department of Community Medicine, Ibrahim Medical College, Dhaka
}

\begin{abstract}
Background and Objectives: Peripheral neuropathy is a complication of diabetes mellitus (DM). Several risk factors may accelerate the development of peripheral neuropathy in DM. The objective of the current study was to determine the risk factors for development of peripheral neuropathy in patients with DM.

Methods: The study was conducted from July 2014 to June 2015 in a large hospital of Dhaka city. A total of 150 diabetic patients of both sexes with and without peripheral neuropathy were enrolled. The investigations included interviewing on clinical history, anthropometry (height, weight, waist- and hip-circumference), blood pressure measurement, estimation of HbA1c, fasting blood glucose and lipids.

Results: Duration of diabetes for more than 5 years was significantly $\left(\chi^{2}=124.39, p<0.001\right)$ associated with peripheral neuropathy. Sequential logistic regression analysis revealed high BMI $\left(>25 \mathrm{Kg} / \mathrm{m}^{2}\right.$; OR=8.8, p <0.001), HbA1c $(>6.5 \%$; OR=5.25, $\mathrm{p}<0.05)$ and higher total cholesterol level (> $200 \mathrm{mg} / \mathrm{dl}$; OR=4.74, $\mathrm{p}<0.05$ ) as the significant risk factors for peripheral neuropathy.

Conclusion: Obesity, hyperglycemia and high total cholesterol were possible risk factors for development of diabetic peripheral neuropathy. Proper glycemic control and prevention of obesity and dyslipidemia could be helpful to avert progression to peripheral neuropathy in diabetic population.
\end{abstract}

IMC J Med Sci 2019; 13(2): 007. EPub date: 23 November 2019

\section{Introduction}

Diabetes mellitus (DM) is a clinical syndrome characterized by hyperglycemia due to relative or absolute deficiency of insulin in the body [1]. World Health Organization (WHO)) has defined the diagnostic criteria of DM as fasting plasma glucose $\geq 7.0 \mathrm{mmol} / \mathrm{L}$, or $\geq 11.1 \mathrm{mmol} / \mathrm{L} 2$ hours after 75 gram of glucose load or $\mathrm{HbA} 1 \mathrm{c} \geq 6.5 \%$ [2].

In Bangladesh the prevalence of DM is about 5.5\% [3]. Peripheral neuropathy is one of the most common complications in patients with type 2 diabetes mellitus [4]. In peripheral neuropathy, damage involves motor and sensory nerves in the peripheral nervous system, sparing neurons in the central nervous system [5]. Diabetic peripheral neuropathy has been defined as the presence of symptoms and/or signs of peripheral nerve dysfunction in people with diabetes after exclusion of other causes. Diabetic peripheral neuropathy can affects $20 \%-50 \%$ of the population with diabetes [6]. A study has reported that the prevalence of diabetic peripheral neuropathy in Bangladesh is about $19.7 \%$ [7].

Several studies have suggested that hyperglycemia is an important risk factor for development of neuropathy and intensified metabolic control can

Address for Correspondence:

Dr. Taslima Akter, Assistant Professor, Department of Physiology, Ibrahim Medical College, 1/A Ibrahim Sarani, Segunbagicha, Dhaka, Bangladesh. Email: taslimaakter783160@gmail.com 
prevent or delay the development of diabetic peripheral neuropathy [8]. Glycosylated hemoglobin act as an index of long term diabetes control and $\mathrm{HbA} 1 \mathrm{c} \leq 7.0 \%$ is considered as good glycemic control [8]. Several studies have suggested that obesity and hyperlipidemia as potential risk factors for diabetic peripheral neuropathy. Elevated triglyceride and obesity increase the risk for future development of peripheral neuropathy in diabetic patients $[9,10]$. However, Bansal et al has reported that obesity might not correlate with neuropathy in diabetic patients [11]. The study has found that $\mathrm{BMI}$ and waist circumference as same in diabetic patients with and without neuropathy. It has been observed that in Asian population, the comorbidities of obesity occur at a lower BMI than in other ethnic groups of the world [12]. Also, the severity of diabetic peripheral neuropathy depends on the duration of the diabetes and the degree of glycemic control [13].

Therefore, it appears that uncontrolled glycemia, obesity, hyperlipidemia and longer duration of DM are possible risk factors for development of peripheral neuropathy among diabetic cases. However, limited research work has been conducted to assess the risk factors associated with peripheral neuropathy in Bangladeshi population. The aim of the present study was to find out the risk factors for peripheral neuropathy among Bengali diabetic patients.

\section{Methods}

Study population and place: This cross sectional study was conducted over a period of one year from July 2014 to June 2015. The study was approved by Ethical review committee of Dhaka Medical College, Dhaka. The nature, purpose and benefits of the study were explained to each participant in details and informed written consent was obtained. Study population were selected from indoor and outpatients of BIRDEM General Hospital in Dhaka city. Study population consisted of 150 cases of DM of both sexes and divided into two groups namely Group A and Group B. Group A consisted of cases who had only DM without peripheral neuropathy and Group B had agematched DM cases with peripheral neuropathy. Age, sex, duration of diabetes, history of hypertension and other co-morbidities were recorded. Diagnosis of DM was based on fasting plasma glucose $\geq 7.0 \mathrm{mmol} / \mathrm{L}$ or $\mathrm{HbA} 1 \mathrm{c} \geq 6.5 \%$ [2] Peripheral neuropathy was diagnosed by clinical features (numbness, burning and tingling sensation, fatigue and cramping pain) and by nerve conduction velocity test $[7,9]$.

Anthropometry: Anthropometric measurements namely height, weight, waist and hip circumference were taken to assess the general and central obesity status. The waist circumference was measured in a standing position between the lower border of the $12^{\text {th }}$ rib and the highest point of the iliac crest on mid-axillary line at the end of normal expiration. Body mass index (BMI) was calculated using weight in kilogram divided by height in meter and expressed as $\mathrm{kg} / \mathrm{m}^{2}$. Waist-to-hip ratio (WHR) was calculated as waist measurement divided by hip circumference. BMI was used for determining the general obesity while the WHR indicated central obesity. Blood pressure of each participant was measured after ensuring at least ten minutes of rest. All the information was recorded systematically in a predesigned data sheet.

Collection of blood and biochemical tests: With aseptic precaution, $5 \mathrm{ml}$ of venous blood was collected from antecubital vein by a disposable plastic syringe from each participant for estimation of fasting blood glucose (FBS), HbA1c, triglyceride (TG) and total cholesterol (TC).

Statistical analyses: All the parameters were expressed as mean \pm SD. Chi square was done to find out association between variables and unpaired Student's ' $\mathrm{t}$ ' test was performed to compare means between the two groups. Sequential logistic regression analysis was carried out to determine risk factors for developing neuropathy; $p$ value $<0.05$ was considered as level of significance. Estimates were reported as odds ratios (OR) with 95\% confidence interval $(\mathrm{Cl})$. Statistical analysis were performed by using a computer based statistical program SPSS (version 23).

\section{Results}

A total of 150 DM cases were enrolled of which Group-A had 75 DM cases without peripheral neuropathy and Group-B had 75 age matched DM 
cases with peripheral neuropathy. Age, blood pressure, anthropometric and biochemical parameters of Group-A population were significantly $(p<0.05$ or 0.001$)$ less than that of Group-B (Table-1). Table- 2 shows that there was no significant association of specific sex with the occurrence of peripheral neuropathy. But peripheral neuropathy was significantly $\left(\chi^{2}=\right.$ 124.39, $p<0.001)$ higher in cases having diabetes for more than 5 years of duration than those who had diabetes for 1-5 years. Sequential logistic regression revealed that higher $\mathrm{BMI}\left(\geq 25.0 \mathrm{~kg} / \mathrm{m}^{2}\right)$, $\mathrm{HbA} 1 \mathrm{c}(\geq 6.5 \%)$ and increased total cholesterol (> $200 \mathrm{mg} / \mathrm{dl}$ ) were associated significantly with the occurrence of diabetic peripheral neuropathy. Diabetic cases with high BMI $\left(\geq 25 \mathrm{~kg} / \mathrm{m}^{2}\right), \mathrm{HbA} 1 \mathrm{c}$ $(\geq 6.5 \%)$ and higher total cholesterol $(\geq 200 \mathrm{mg} / \mathrm{dl})$ had almost 9 (OR - 8.8; Cl-3.0,25.9; p<0.001), 5 (OR-
5.25; $\mathrm{Cl}-1.75,15.78 ; \mathrm{p}<0.05)$ and 5 (OR-4.74; $\mathrm{Cl}-$ $1.81,12.4 ; \mathrm{p}<0.05)$ times higher risk of developing diabetic peripheral neuropathy respectively (Table3). Waist circumference and triglycerides were not found as risk factors for peripheral neuropathy.

\section{Discussion}

The present study investigated the possible anthropometric and biochemical risk factors related to development of peripheral neuropathy in ethnic Bengali diabetic patients. Gender was not found to be associated with development of peripheral neuropathy while we found its significant association with longer duration of diabetes ( $>5$ years) in our cases. Similar observation was reported with South Indian

Table-1: Comparative profiles of Group-A and Group-B study population

\begin{tabular}{lccc}
\hline Variable & $\begin{array}{c}\text { Group A } \\
\mathbf{N = 7 5}\end{array}$ & $\begin{array}{c}\text { Group B } \\
\mathbf{N = 7 5}\end{array}$ & p value \\
\hline Age (years) & $37.75 \pm 6.13$ & $44 \pm 5.92$ & $<0.001$ \\
SBP (mm Hg) & $117.53 \pm 5.66$ & $120.67 \pm 6.59$ & $<0.005$ \\
DBP (mm Hg) & $78.13 \pm 3.47$ & $80.13 \pm 3.58$ & $<0.002$ \\
HbA1c (\%) & $6.25 \pm .87$ & $7.93 \pm 1.66$ & $<0.001$ \\
BMl (Kg/m $\left.{ }^{2}\right)$ & $22.71 \pm 1.71$ & $27.14 \pm 4.54$ & $<0.001$ \\
Waist $(\mathrm{cm})$ & $83.40 \pm 6.72$ & $92.37 \pm 9.33$ & $<0.001$ \\
WHR & $.94 \pm .02$ & $.96 \pm .05$ & $<.05$ \\
TG (mg/dl) & $136.20 \pm 50.87$ & $195.74 \pm 71.15$ & $<0.001$ \\
TC (mg/dl) & $149.87 \pm 45.59$ & $217.15 \pm 39.41$ & $<0.001$ \\
\hline
\end{tabular}

Note: Group-A: DM cases without peripheral neuropathy, Group-B: DM with peripheral neuropathy, SBP: Systolic blood pressure, DBP: Diastolic blood pressure, WHR: Waist-hip ratio, HbA1c: Glycated , TG: Triglyceride; TC= Total cholesterol,

Table-2: Association of peripheral neuropathy with gender and duration of diabetes

\begin{tabular}{lccc}
\hline Variables & Total number & $\begin{array}{c}\text { Positive for DPN } \\
\mathbf{N}(\%)\end{array}$ & $\chi^{2}$ and $\mathbf{p}$ value \\
\hline Sex & 79 & $41(59.89)$ & \\
Male & 71 & $34(47.88)$ & $\chi^{2}=0.24, p=0.624$ \\
Female & & & \\
Duration of diabetes & 82 & $7(8.54)$ & \\
1-5 Years & 68 & $68(100)$ & $\chi^{2}=124.39, p<0.001$ \\
$>5$ years &
\end{tabular}

DPN=Diabetic peripheral neuropathy 
Table-3: Association of risk factors with diabetic peripheral neuropathy

\begin{tabular}{|c|c|c|c|c|}
\hline \multirow[b]{2}{*}{ Variables } & \multirow[b]{2}{*}{$\begin{array}{c}\text { Group-A } \\
n(\%)\end{array}$} & \multirow{2}{*}{$\begin{array}{l}\text { Group-B } \\
\mathrm{n}(\%)\end{array}$} & \multicolumn{2}{|c|}{ Multivariate } \\
\hline & & & $\begin{array}{l}\text { Adjusted OR } \\
95 \% \mathrm{Cl}\end{array}$ & $p$ value \\
\hline \multicolumn{5}{|l|}{ HbA1c( \%) } \\
\hline$<6.5$ & $37(75.5)$ & $12(24.5)$ & Ref & \\
\hline$\geq 6.5$ & $38(37.6)$ & $63(62.4)$ & $5.25(1.75,15.78)$ & $<0.05$ \\
\hline \multicolumn{5}{|l|}{ BMI $\left(\mathrm{kg} / \mathrm{m}^{2}\right)$} \\
\hline$<25.0$ & 66 (73.3) & $24(26.7)$ & Ref & \\
\hline$\geq 25.0$ & $9(15)$ & $51(85)$ & $8.8(3.0,25.9)$ & $<0.001$ \\
\hline \multicolumn{5}{|l|}{$W C(\mathrm{~cm})$} \\
\hline$<88(\mathrm{~F}) /<102(\mathrm{M})$ & 64 (58.7) & $45(41.3)$ & Ref & \\
\hline$\geq 88(\mathrm{~F}) / \geq 102(\mathrm{M})$ & $11(26.8)$ & $30(73.2)$ & $1.33(0.4,4.4)$ & 0.646 \\
\hline \multicolumn{5}{|l|}{ TC (mg/dl) } \\
\hline$<200$ & 64 (72.7) & $24(27.3)$ & Ref & \\
\hline$\geq 200$ & $11(17.7)$ & $51(82.3)$ & $4.74(1.81,12.4)$ & $<0.05$ \\
\hline \multicolumn{5}{|l|}{$\mathrm{TG}(\mathrm{mg} / \mathrm{dl})$} \\
\hline$<160$ & $52(67.5)$ & $25(32.5)$ & Ref & \\
\hline$\geq 160$ & $23(31.5)$ & $50(68.5)$ & $1.85(0.71,4.81)$ & 0.208 \\
\hline
\end{tabular}

Note: Group-A: DM cases without peripheral neuropathy, Group-B: DM with peripheral neuropathy.

diabetic cases [14]. Sequential logistic regression analysis revealed that higher $\mathrm{HbA1C}$ was a significant (OR $-5.25, \quad p<0.05$ ) risk factor for developing peripheral neuropathy in our study population. Similar findings were reported earlier in studies conducted in Bangladeshi diabetic population [7]. The current study found that higher $\mathrm{BMI}$ in DM cases as a significant risk factor for peripheral neuropathy. Significant association of peripheral neuropathy with obesity has been reported by others $[10,15,16]$. We also observed higher level of total cholesterol as a significant risk factor for peripheral neuropathy as reported in other studies $[9,10,17,18]$. Reactive oxygen species induced by obesity and dyslipidemia might be responsible for development of peripheral neuropathy $[19,20]$.

This study concluded that higher BMI and elevated level of $\mathrm{HbA1c}$ and cholesterol can be the risk factors for the development of peripheral neuropathy in diabetes mellitus. Therefore, obesity management and maintaining normal glycemic status and cholesterol level can prevent or delay the development of peripheral neuropathy in diabetics.

\section{References}

1. Frier BM, Fisher M. Diabetes mellitus. In: Nicki $R$, Brian R, Stuart $H$, editors. Davidson's Principle and Practice of Medicine. $21^{\text {st }}$ ed. New Delhi. Elsevier; 2010. 735-833.

2. Seino $Y$, Nanjo K, Tajima N, Kodawaki $T$, Kasiwagi A, Araki E. Report of the committee on the classification and diagnostic criteria of diabetes mellitus. J Diabetes Invest. 2010; 1(5): 212-28.

3. IDF Diabetes Atlas. $6^{\text {th }}$ ed. Brussels, Belgium: International Diabetic Federation; 2013.

4. Kakrani AL, Gokhale VS, Vohra KV, Vohra KV, Chaudhary N. Clinical and nerve conduction study correlation in patients of diabetic neuropathy. $J$ Assoc Physician India. 2014; 62: 24-27.

5. Chaudhry V. Peripheral neuropathy. In Hauser $\mathrm{SL}$, editor. Harrison's Neurology in Clinical Medicine. $2^{\text {nd }}$ ed. New Delhi: The McGraw-Hill 2010: 525-49.

6. Boulton A. The diabetic foot: Epidemiology, risk factors and the status of care. Diabetes Voice. 2005; 50(Special Issue): 5-7. 
7. Morkrid K, Ali L, Hussain A. Risk factors and prevalence of diabetic peripheral neuropathy: A study of type 2 diabetic outpatients in Bangladesh. Int J Diabetic Dev. 2010; 30(1): 11-17.

8. Booya F, Bandarian F, Larijani B, Pajouhi M, Nooraei M, Lotfi J. Potential risk factors for diabetic neuropathy: A case control study. BMC Neurol. 2005; 24(5): 2371-75.

9. Wiggin TD, Sullivan KA, Pop-Busui R, Amato A, Sima AA, Feldman EL. Elevated triglycerides correlate with progression of diabetic neuropathy. Diabetes. 2009; 58: 1634-1640.

10. Smith AG, Singleton JR. Obesity and hyperlipidaemia are risk factors for early diabetic neuropathy. J Diabetes Complication. 2013; 27(5): 436-442.

11. Bansal D, Gudala K, Muthyala H, Esam HP, Nayakallu R, Bansali A. Prevalence and risk factors of development of peripheral diabetic neuropathy in type 2 diabetes mellitus in a tertiary care setting. J Diabetes Investig. 2014 5(6): 714-21.

12. Misra A, Khurana L. Obesity-related noncommunicable diseases: South Asians vs White Caucasians. Intern J Obes. 2011; 35: 167-87.

13. Salem K, Ammari $F$, Khader $Y$, et al. Elevated glycosylated hemoglobin is associated with subclinical neuropathy in neurologically asymptomatic diabetic patients: a prospective study. J Clin Neurophysiol. 2009; 26: 50-53.
14. Ashok S, Ramu M, Deepa R, Mohan V. Prevalence of neuropathy in type 2 diabetic patients attending a diabetes centre in South India. J Assoc Physicians India. 2002; 50: 546-550.

15. Ziegler D, Rathmann W, Dickhaus T, Meisinger $C$, Mielch A. Prevalence of polyneuropathy in pre-diabetes and diabetes is associated with abdominal obesity and macroangiopathy. Diabetes Care. 2008; 31: 464-69.

16. Li L, Chen J, Wang J, et al. Prevalence and risk factors of diabetic peripheral neuropathy in type 2 diabetes mellitus patients with overweight/ obese in Guangdong province, China. Primary Care Diabetes. 2015; 9(3): 191-195.

17. Pawde PP, Thampi RR, Renish RK, Resmi RU, Vivek RU. Prevalence and risk factors of diabetic peripheral neuropathy among type 2 diabetic patients presenting to SMIMS hospital, Tamil Nadu. Int J Med Sci Public Health. 2013; 2(1): 73-76.

18. Al-Ani, Marwan S, Al-Nimer, et al. Dyslipidemia as a contributory factor in etiopathogenesis of diabetic neuropathy. Indian J Endocrinol Metab. 2011; 15(2): 110-14.

19. Vincent, Taylor. Biomarkers and potential mechanisms of obesity-induced oxidant stress in humans. Int J Obes. 2006; 30: 400-18.

20. Farmer KL, Li C, Dobrowsky RT. Diabetic peripheral neuropathy: should a chaperone accompany our therapeutic approach. Pharmacol Rev. 2012; 64(4): 880-900. 